\title{
Primary Intra-articular and Extra-articular Synovial Chondromatosis in a Child: A Rare Cause of Shoulder Pain in Children
}

\author{
Burcin Agridag Ucpinar and Cennet Sahin \\ Department of Radiology, Sisli Hamidiye Etfal Training and Research Hospital, Istanbul, Turkey
}

\begin{abstract}
Synovial chondromatosis is a rare condition with chondroid metaplasia of the synovial membrane and multinodular proliferation of the synovial membrane of the joints, tendons and bursae without any certain etiology. The disease generally presents in monoarticular form; and the most commonly involved joint is the knee. It commonly occurs in third and fifth decades of life. Synovial chondromatosis of the shoulder in children is extremely rare; and up to now, only two cases have been reported in the literature. Herein, we report synovial chondromatosis of the shoulder joint in a child with both intraarticular and extraarticular involvement. To the best of the authors' knowledge, this is the first case in the literature with both intra- and extra-articular involvement of synovial chondromatosis of the shoulder joint in children.
\end{abstract}

Key Words: Synovial chondromatosis, Metaplasia, Children.

How to cite this article: Ucpinar BA, Sahin C. Primary Intra-articular and Extra-articular Synovial Chondromatosis in a Child: A Rare Cause of Shoulder Pain in Children. J Coll Physicians Surg Pak 2020; 30(12):1345-1347.

\section{INTRODUCTION}

Synovial chondromatosis is a rare condition with chondroid metaplasia of the synovial membrane and multinoduler proliferation of the synovial membrane of the joints, tendons and bursae without any certain etiology. ${ }^{1,2}$ The nodules may enlarge and detach from the synovium. The disease generally presents in monoarticular form and the most commonly involved joint is the knee (50-65\% of the cases), followed by hip. ${ }^{2}$ Shoulder involvement is rare with $5 \%$ occurrence rate. It commonly occurs in third and fifth decades of life and twice common in male population. ${ }^{3}$ Synovial chondromatosis of the shoulder in children is extremely rare; and up to now, only two cases have been reported in the literature. ${ }^{4,5}$

Herein, we report synovial chondromatosis located in the shoulder joint of a child with both intraarticular and extraarticular involvement. To the best of the authors' knowledge, this is the first case in the literature of synovial chondromatosis with both intra-and extraarticular involvement in a child.

Correspondence to: Dr. Burcin Agridag Ucpinar, Department of Radiology, Sisli Hamidiye Etfal Training and Research Hospital, Istanbul, Turkey

E-mail: drburcinagridag@gmail.com

Received: August 08, 2019; Revised: November 08, 2019; Accepted: November 26, 2019

DOI: https://doi.org/10.29271/jcpsp.2020.12.1345

\section{CASE REPORT}

A 17-year boy was admitted to orthopaedic outpatient clinic with a 6-month history of the left shoulder pain and restriction in the shoulder movements. In history taking, the patient stated that the pain increased gradually and no shoulder trauma and swelling or bruising of the shoulder has happened as he remembered. The pain was localised to superior and anterior aspects of the glenohumeral joint. There was no remarkable deformity around the left shoulder on inspection. On physical examination, there was decreased range of motion with limitation in active and passive abduction over $90^{\circ}$ and internal rotation. The blood tests were normal and the family history was not remarkable. X-Ray of the shoulder showed multiple well defined osseous intra- and extra-articular loose bodies (Figure 1a). Computerised tomography (CT) revealed multiple calcified fragments in the same location (Figure 1b). There was no remarkable extrinsic bone erosion. Magnetic resonance imaging (MRI) showed multiple loose bodies within the glenohumeral joint and also the subacromial bursa, around the long tendon of the biceps, and around the rotator cuff muscle tendons. The fragments were hypointense on T1-weighted MRI and hyperintense on T2-weighted MRI with hypointense areas inside that reflected the high water content of the cartilaginous lesions with accompanied inner calcific areas (Figure 2 ). The radiologic findings were pathognomonic for primary synovial chondromatosis and the patient was referred to orthopedic tumor surgeons for arthrotomy to remove the loose bodies with concommittant synovectomy. 


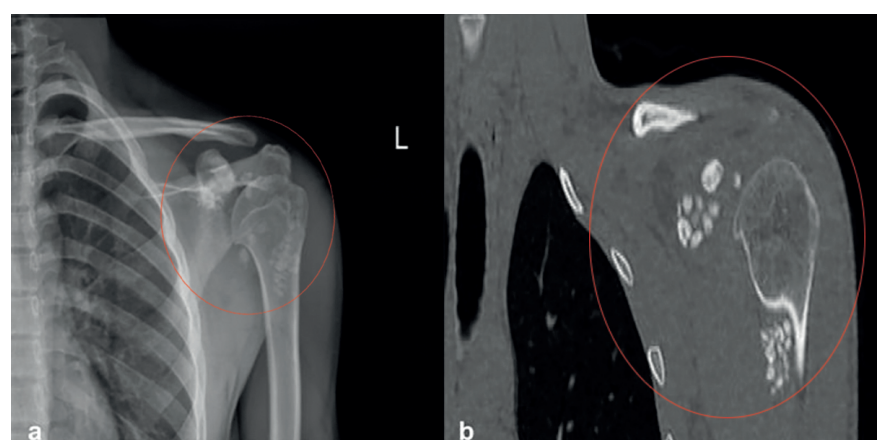

Figure 1: Postero-anterior X-Ray (1a) and coronal computed tomography (CT) imaging (1b) of left shoulder. Multiple osseous loose bodies are seen located both in glenuhumeral joint and extraarticular tissues (red circles).

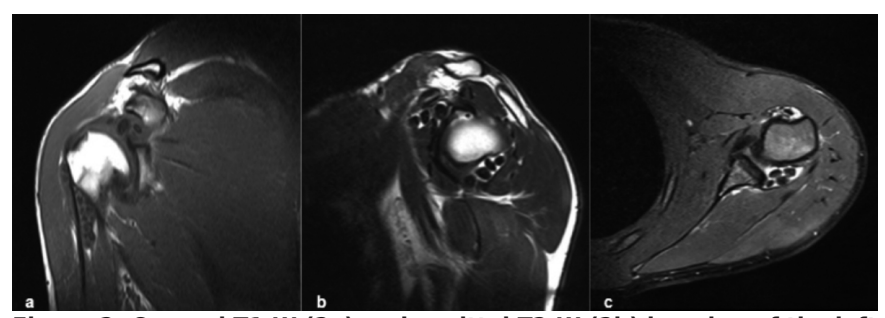

Figure 2: Coronal T1-W (2a) and sagittal T2-W (2b) imaging of the left shoulder. Intraarticular hypointense loose bodies are seen (black arrows). Transverse PD imaging (2c). Peritendineal loose bodies could clearly be identified around the long head of biceps tendon (red circle).

\section{DISCUSSION}

Synovial chondromatosis was first described by Reichel in 1900 and termed as a rare benign disorder of the synovial lining of joints, bursae and tendon sheaths characterized by chondroid metaplasia with multinodular proliferation. ${ }^{5}$ Primary and secondary forms of the disease have been described. Secondary synovial chondromatosis is the result of a mechanical injury to the joint and most commonly related to degenerative arthropathy. ${ }^{2}$ Even primary form has no certain etiology; trauma, infections and fibroblast growth factor-9 (FGF-9) as possible etiologies have been mentioned in the literature. ${ }^{3}$ Primary synovial chondromatosis (PSC) is a monoarticular disease that usually affects the large joints. The age range of the patients is wide. It mostly presents in between $3^{\text {rd }}$ and $5^{\text {th }}$ decades of life with male predominance (M:F ratio of $2: 1$ ). ${ }^{2,3}$ It can affect any synovial joint; shoulder joint involvement is rare with a prevalence of $5 \%$ and the extra-articular extension is even rarer. ${ }^{6}$ Synovial chondromatosis of the shoulder and other joints affecting children have been reported before ${ }^{1-4} \mathrm{McCl}$ cle and colleague reported a case of PSC of the shoulder in a 12year boy. ${ }^{4}$ Dwidmuthe atal. reported a a case of primary extra-articular synovial chondromatosis of the biceps tendon sheath in an 8-year boy. ${ }^{1}$ In their case, there was no co-occurrence of intra- and extraarticular involvement of the shoulder joint. This point was the distinctive feature of our case. Clinical symptoms include pain, swelling, and restriction of the range of motion and typically gradually increase during the course of the disease. The duration of the clinical symptoms before the diagnosis is generally long; with an average of 5 years. ${ }^{2}$

Milgram divided the disease into three phases. In phase one, there is active synovial disease with no loose bodies. In phase two, also called the transitional phase, there are osteochondral nodules in both in the synovial membrane and the joint space floating freely. In phase three, multiple osteochondral bodies are seen with no intra-synovial disease. ${ }^{7}$

The X-ray imaging findings may be normal in 5-30\% cases. In general, radiographs reveal multiple calcifications usually of similar size and shape. In rare cases, the chondroid bodies may coalesce and form a large mineralised mass. CT and MRI give opportunity to optimally evaluate the extrinsic bone erosion. Additionally, CT and MRI, owing to cross-sectional imaging capabilities, reveal the intra-articular and extra-articular involvement and precise localisation of the loose bodies, accompanying joint effusion, and extrinsic bone erosion. Malignant transformation of PSC to chondrosarcoma is a rare but serious condition with an estimated incidence in the range of $1-5 \%$. CT and MRI have a crucial role in detecting possible malignanttransformation. MRI can also be helpful to demonstrate bone marrow edema, bony invasion or soft tissue extension. ${ }^{2}$

The treatment of choice for synovial chondromatosis is surgical resection. Traditional treatment for synovial chondromatosis is open arthrotomy, synovectomy and complete removal of the free fragments. However, recent advances in arthroscopic techniques and methods has led to widening of the indications for arthroscopic treatment. Open and closed arthroscopic methods can be used in the treatment of synovial chondromatosis. ${ }^{8}$ Synovectomy and excision of the chondral bodies are regarded as the optimal treatment. Extra-articular involvement is important to detect in imaging during preoperative evaluation because it cannot be treated through arthroscopic techniques. ${ }^{2}$ In recurrent disease, which has been noted in 3-23\% of cases after surgical synovectomy with removal of chondral fragments, radiotherapy was found to be useful. FGF-9 inhibitors have been suggested as a non-operative treatment of PSC. Malignant transformation of PSC usually requires amputation. ${ }^{2,3}$

In conclusion, it is important that radiologists and orthopedic surgeons keep PSC in mind while approaching synovial joint pain in children. Preoperative detailed radiological evaluation and detection of the any intra-articular, bursal and peritendineal chondroid bodies are crucial to direct the orthopedic surgeon during operation. Additionally, patients should be informed well about the possible recurrence and malignant transformation risks and should be followed accordingly.

\section{PATIENT'S CONSENT:}

Written informed consent was obtained from the patient and the family to report this case study.

\section{CONFLICT OF INTEREST:}

The authors declared no conflict of interest.

\section{AUTHORS' CONTRIBUTION:}

BAU, CS: Involved in the conception, design and interpretation, wrote the manuscript and collected data, reviewed relevant published reports and provided the images. Read and approved the final manuscript. 


\section{REFERENCES}

1. Dwidmuthe SC, Nemade AS, Agrawal S, Pathak A. Rare case of extra-articular synovial chondromatosis of biceps tendon sheath in 8 years male child. J Orthop Case Rep 2014; 4(4):33-6. doi: 10.13107/jocr.2250-0685.221.

2. Murphey MD, Vidal JA, Fanburg-Smith JC, Gajewski DA. Gajewski. Imaging of synovial chondromatosis with radiologic-pathologic correlation. Radiographics 2007; 27(5):1465-88. doi: 10.1148/rg.275075116.

3. Srinivas K, Rajaiah D, Ramana Y, Kumar PK. Synovial chondromatosis in a young child: A rare presentation. J NTR Univ Health Sci 2015; 4:36-8.

4. Lauren M, David L. A rare cause of shoulder pain in pediatrics. Pediatrics 2018; 142:408. doi:10.1542/peds.
142.1_MeetingAbstract.408.

5. Reichel PF. Chondromatose der Kniegelenkkapsel. Arch Klien Chir 1900; 61:717-21.

6. Costa F, Freitas JP, Coutinho M, Malcata A. Stony shoulder: An exuberant case of glenohumeral synovial chondromatosis with extra-articular extension. BMJ Case Rep 2018; 2018. pii: bcr-2018-225718. doi: 10.1136/ bcr2018- 225718.

7. Milgram JW. Synovial osteochondromatosis: A histopathological study of thirty cases. J Bone Joint Surg Am 1977; 59:792-801.

8. Duymus TM, Yucel B, Mutlu S, Tuna S, Mutlu H, Komur B. Arthroscopic treatment of synovial chondromatosis of the shoulder: A case report. Ann Med Surg (Lond) 2015; 4(2): 179-82. 